lization of the perforating veins will probably be used more than phlebography, but it is unlikely to be adopted for investigating all varicose veins because, apart from the technical assistance and skill needed, the apparatus is expensive. Until a simple, inexpensive bedside method of detection is devised, thermography is likely to be used in the same way as phlebography, for the difficult recurrent case. But if this addition to our methods of investigation were to be used widely the results of the treatment of varicose veins would be noticeably improved.

\section{Culdocentesis and Ectopic Pregnancy}

Classically, ruptured ectopic pregnancy presents as an acute surgical emergency, and it still contributes to maternal mortality. ${ }^{1}$ But a less dramatic clinical picture is more common, though the correct diagnosis can usually be suspected from careful history-taking and examination coupled with a keen awareness of the possibility. The clinical features include a short period of amenorrhoea or a recent abnormal period (though the menstrual history may be normal), lower abdominal pain characteristically spasmodic and severe, tenderness, and a scanty vaginal loss of dark blood. Pelvic examination may elicit considerable and often exquisite pain on moving the cervix or a mass in the posterior or lateral fornices.

In the "chronic" condition associated with tubal abortion or mole, several of these features may be absent and diagnosis may be difficult. Pregnancy tests are not usually helpful, and pelvic examination under anaesthesia and examination of the endometrium for decidual change may give misleading results. Culdocentesis has long been advocated as a means of detecting intraperitoneal haemorrhage, but its popularity seems to have declined in Great Britain because of a reputation for unreliability. ${ }^{4}$ But in Lusaka, Zambia, Drs. Cynthia Lucas and A. M. Hassim have found the technique to be of great value, and they report in the B.M.F. this week (page 200) their experience with its use in 155 of 199 cases of suspected ectopic pregnancy.

Culdocentesis provided the correct diagnosis in 148 cases ( 55 negative and 93 positive). There were three false negative results (including two in which the ectopic gestation had not leaked blood into the peritoneal cavity) and four false positive results (two with pelvic infection and two with conditions which required laparotomy in any case). In the remainder culdocentesis was not attempted as the diagnosis was not in doubt. The technique, therefore, achieved a diagnostic accuracy of $93 \%$.

This higher percentage of correct diagnosis than in other series $\left(55 \%,{ }^{2} 72 \%{ }^{4}\right)$ Drs. Lucas and Hassim attribute to their more frequent use of the procedure. J. T. Armstrong and colleagues reported a comparable diagnostic accuracy of $89 \%{ }^{3}$

\footnotetext{
1 Report on Confidential Fnquiries into Maternal Deaths, England and Wales 1964-1966. London, H.M.S.O. 1969.

Bobrow, M. L., and Winkelstein, L. B., American fournal of Obstetrics and Gynecology, 1955. 69, 101.

3 Armstrong, J. T., Wills, S. H., Moore, I., and Lauden, A. E., American fournal of Obstetrics and Gynecology, 1959, 77, 364.

4 Douglas, C. P., British Medical fournal, 1963, 2, 838.

5 Steptoe, P. C., Laparoscopy in Gymaecology. Edinburgh, E. and S. Livingstone. 1967.

6 Frangenheim, H., Geburtshilfe und Frauenheilkrankene, 1964, 24, 470.

7 Siövall, A., in Steptoe, P. C., Laparoscopy in Gynaecology, p. 57 Edinburgh, $E$. and S. Livingstone. 1967.
}

Lucas and Hassim found culdocentesis to be the most important single diagnostic aid in their cases. They usually performed it as a side-ward procedure without an anaesthetic, using a 5-in. $(12.5-\mathrm{cm}$.) size 18 needle inserted into the pouch of Douglas for about 1 in. $(2.5 \mathrm{~cm}$.). In Zambia pelvic infection is the most common differential diagnosis of ectopic gestation, but with their technique the authors have avoided the possible risk of perforating a pyosalpinx or adjacent bowel.

The authors do not favour laparoscopy because they find that pelvic adhesions may preclude an adequate view or that the large trocar may damage adherent bowel. A different view seems to be held both in Britain and on the Continent of Europe. P. C. Steptoe ${ }^{5}$ considers that the possibility of ectopic gestation is one of the principal indications for laparoscopy and that it may also show other conditions not associated with haemoperitoneum which require laparotomy. H. Frangenheim ${ }^{6}$ noted that laparoscopy increased the frequency of diagnosis of intact extrauterine pregnancies from 9 to $23 \%$.

There was a relatively high incidence of acute cases in the Zambian series, and it may be that the cases described by Lucas and Hassim presented, on average, at a later stage of the condition than is usual in Britain. It would be interesting to know the results of laparoscopic examination in a Zambian series similar to those described this week. Though acute pelvic inflammatory disease is often thought to contraindicate laparoscopy, A. Sjövall ${ }^{7}$ has used it extensively without complications in suspected acute salpingitis and found that the clinical diagnosis was often incorrect.

Laparoscopy requires an experienced operator and expert general anaesthesia, but it is likely to be of more value than culdocentesis as it can contribute more to the overall management of a particular clinical problem than simply by confirming or refuting the diagnosis of haemoperitoneum. In the developing countries, however, where facilities may be limited and patients may tend to present at an advanced stage of the condition, the simple technique of culdocentesis has obvious advantages and is apparently of great value. Though C. P. Douglas ${ }^{4}$ considered that the number of false positive results he obtained in acute salpingitis in Jamaica limited the value of the technique, the excellent results reported by Lucas and Hassim are likely to encourage its wider use for the diagnosis of ectopic pregnancy in similar circumstances.

\section{Computers for Transplantation}

Rejection of transplanted tissue depends on the recognition of the donated tissue by the recipient and its immune destruction. The antigens that are recognized in this process are called histocompatibility factors. They include the substances of the red-blood-cell groups and also glycoproteins present in all nucleated cell membranes but absent from red cells. These glycoproteins are detected in the laboratory by means of agglutination or cytotoxic effects on white blood cells. Antisera are used from patients who have rejected transplants, recipients of multiple blood transfusions, or patients who have become immunized as a result of multiple pregnancies.

Although the definition of histocompatibility antigens is not yet complete, it is clear that in man; as in several other mammalian species, there is one strong histocompatibility 
system, analogous to $A$ and $B$ red cell antigens, which is inherited in a similar way to the red-cell groups. The chances, therefore, of satisfactory donors of organ transplants being found within members of a family are much higher than between unrelated individuals. This is probably the main reason for the much better results obtained with kidney transplants from familial donors. About $80 \%$ of these patients have functioning transplants two years after operation compared with only $40 \%$ of those whose kidneys came from the cadavers of unrelated people. Since the chances of there being a suitable familial donor are rather slim for a patient with irreversible renal disease, improvement in the results of cadaveric renal transplantation is desirable. To record centrally the tissue and red-blood-cell groups of all patients awaiting transplantation and to match donor kidneys, as they become available, to the most appropriate recipient is therefore a logical development.

Professor J. J. Van Rood, in Leiden, inaugurated such a system for the Benelux countries ${ }^{1}$ two years ago-the organization being called Eurotransplant. A similar system operates in Scandinavian countries, and such a scheme has also been suggested for Great Britain. For a country with a high-density population the chances of obtaining a match that can be utilized in practice is a realistic proposition, as Professor Van Rood has already shown. A pool of a minimum of 200 recipients is likely to have within it two individuals for whom

\section{Cardiac Failure and Folate Deficiency}

Megaloblastic anaemia due to folate deficiency is not a primary disorder but is associated with well defined clinical states. ${ }^{1}$ Thus it frequently complicates pregnancy, particularly when malnutrition is present and when the mother is carrying twins. It may occur in a patient on anticonvulsant drugs, particularly diphenylhydantoin. The same risk attends patients suffering from malabsorption syndrome. Indeed the first clue pointing to the diagnosis often comes from the laboratory report of a macrocytic blood picture. Again, failure of haemopoiesis in chronic myelofibrosis ${ }^{2}$ or chronic haemolytic anaemia should always raise the question of a complicating megaloblastic process due to folate deficiency.

Overt megaloblastic anaemia in these disorders, perhaps with the exception of pregnancy and intestinal malabsorption, is relatively infrequent. But clinical disease is only the

1 Chanarin, I., The Megaloblastic Anaemias. Oxford, Blackwell Scient:fic Publications. 1969.

2 Hoffbrand, A. V., et al., Quarterly fournal of Medicine, 1968, 37, 493.

3 Chanarin, I., Dacie, J. V., and Mollin, D. L., British Fournal of Haematology, 1959, 5, 245.

Giles, C., and Shuttleworth, E. M., Lancet, 1958, 2, 1341.

5 Klipstein, F. A., Blood, 1964, 23, 68.

Reynolds, E. H., Milner, G., Matthews, D. M., and Chanarin, I., Quarterly fournal of Medicine, 1966, 35, 521 .

7 Knowles, J. P., Shuster, S., and Wells, G. C., Lancet, 1963, 1, 1138.

Roberts, P. D., Hoffbrand, A. V., and Mollin, D. L., British Medical fournal, 1966, 2. 198.

Partridge, R. E. H., and Duthie, J. J. R., British Medical fournal, $1963,1,89$. 10 Brody, J. I., Soltys, H. D., and Zinsser, H. F., British Heart fournal,
1969, 31, 741.

11 Magnus, E. M., Cancer Research, 1967, 27, 490.

12 Varadi, S., and Elwis, A., British Medical fournal, 1966, 2, 410.

13 Chanarin, I., and Perry, J., Lancet, 1969, 2, 776.

14 Chanarin, I., and Perry, J., British fournal of Haematology, 1968, 14, 297.

15 Herbert, V., Tran

16 Gräsbeck, R., Björksten, F., and Nyberg, W., Nordisk Medicin, 1961

17 Daly, J. J., and Rose, D. P., British Heart fournal, 1966, 28, 698.

18 Hyde, R. D., and Loehry, C. A. E. H., Gut, 1968, 9, 717. any given donor at random can be reasonably well matched. Since kidneys, once cooled after removal from the corpse, deteriorate little within $\mathbf{1 2}$ hours, it is possible to move kidneys anywhere within the United Kingdom and also Northern Europe. In fact this is often possible by ordinary commercial transport, though there are times, such as public holidays and the middle of the night, when an alternative method is needed.

Some patients awaiting renal transplantation, particularly those who have already rejected a graft, have cytotoxic antibodies in their serum. Then a direct cross-match between donor leucocytes and recipient serum must be performed to ensure that the graft will not be immediately rejected by circulating antibodies. This adds to the complexity of the arrangements, since serum from the patients must be brought together with the donor leucocytes either at a peripheral centre or at the main reference laboratory. Just as with red-cell groups, there are rare transplantation types for whom suitable donors are correspondingly uncommon.

Tissue-typing techniques are advancing rapidly, and the degree of prediction for an individual transplant is likely to be very accurate in the next few years. Though the cost of the organization is considerable, the saving in terms of human suffering and dialysis costs for patients with failed grafts makes it important to obtain the best match possible.

1 Belgium, Netherlands, Luxemburg.

tip of the iceberg. Despite the infrequency of megaloblastic anaemia, biochemical evidence pointing to folate deficiency is fairly common in these conditions. Thus in pregnancy evidence of megaloblastic change has been found in only 1 to $2 \%$ of women ${ }^{4}$ but low serum levels of folate and rapid folate clearances in tests are encountered in some $60 \%$ of pregnant women and low red-cell levels of folate in some $30 \% .^{1}$ Similarly, severe megaloblastic anaemia is relatively uncommon in patients receiving treatment for epilepsy, but about half of them have low serum levels of folate ${ }^{5}$ and one-third show megaloblastic features in the bone marrow, though the haemoglobin levels are normal. ${ }^{6}$

In recent years attention has been drawn to disorders in which we do not expect to encounter an overt megaloblastic anaemia as a complication but yet laboratory tests have suggested that subclinical folate deficiency exists more often than it does among hospital patients in general. Such disorders are generalized skin -disease, ${ }^{7}$ tuberculosis,${ }^{8}$ rheumatoid arthritis, ${ }^{9}$ and, more recently noted, congestive cardiac failure. ${ }^{10}$

Subclinical folate deficiency is measured by assay of the serum and red-cell folate concentrations and of the urinary excretion of formiminoglutamic acid. The frequency with which these tests give abnormally low results in patients who require admission to hospital has been reviewed by I. Chanarin. ${ }^{1}$ A low serum level of folate and high urinary excretion of formiminoglutamic acid after a histidine load are found in about one-third of patients admitted to hospital. A low redcell level of folate is less frequent. E. M. Magnus found it low in only 1 out of 102 patients with neoplasms though a low serum level was common. ${ }^{11}$ Chanarin noted that the distribution of red-cell folate values among non-anaemic hospital patients was the same as in healthy medical students. ${ }^{1}$ Reduced values of red-cell folate have been reported in $12 \%$ of aged patients. ${ }^{12}$ Perhaps we should regard a low level of red-cell folate as evidence of true folate defi- 